\title{
Three new species of Domene from China (Coleoptera: Staphylinidae: Paederinae)
}

With 39 figures and 1 map

VOLKER ASSING ${ }^{1}$

${ }^{1}$ Gabelsbergerstraße 2, 30163 Hannover, Germany. - vassing.hann@t-online.de Published on 2015-06-30

\section{Summary}

Three species of Domene FAUVEL, 1873 from China, are described and illustrated: Domene (Macromene) affimbriata spec. nov. (southeastern Yunnan: Dawei Shan near Pingbian), D. (M.) praefigens spec. nov. (eastern Yunnan: region to the north, northwest, and northeast of Kunming), and D. (M.) emeiana spec. nov. (Sichuan: Emei Shan). The distributions of the new species and other named species of the genus in China and Taiwan are mapped. Domene now includes 64 named species, 15 of which have been recorded from China (13) and Taiwan (2).

\section{Key words}

Coleoptera, Staphylinidae, Paederinae, Lathrobiina, Domene, Palaearctic region, China, Yunnan, Sichuan, taxonomy, new species, distribution map

\section{Zusammenfassung}

Drei Arten der Gattung Domene Fauvel, 1873 aus China, werden beschrieben und abgebildet: Domene (Macromene) affimbriata spec. nov. (Südost-Yunnan: Dawei Shan bei Pingbian), D. (M.) praefigens spec. nov. (Ost-Yunnan: nördliche Umgebung von Kunming), und D. (M.) emeiana spec. nov. (Sichuan: Emei Shan). Die Verbreitung der neuen Arten sowie die Gesamtverbreitung der Gattung in China und Taiwan werden anhand einer Karte illustriert. Domene enthält derzeit 64 beschriebene Arten, von denen 15 in China 13) und Taiwan (2) vorkommen.

\section{Introduction}

The lathrobiine genus Domene Fauvel, 1873, whose distribution is confined to the southern Palaearctic region and adjacent parts of the Oriental region (North Vietnam, North Burma, Laos), was previously represented by 61 described species in six subgenera of partly doubtful status. Four of these subgenera with a total of 42 species are confined to the West Palaearctic: the nominate subgenus (22 species, including D. giachinoi AssING, 2007, D. miranda Assing, 2010, and D. ziui PAvićević et al., 2014), Lathromene КосH, 1938 (10 species),
Canariomene Oromí \& Hernández, 1986 (5 species), and Spelaeomene EsPaÑol, 1977 (5 species). The East Palaearctic and North Oriental Domene fauna comprises 19 described species, one of doubtful generic assignment from North India in Neodomene BLACKWELDER, 1939 and 18 in Macromene CoIffait, 1982. Species of Macromene have been recorded from China (10 species), Taiwan (2), Japan (5), Russia (2), Korea (2), North Vietnam (1), and Burma (1). Females of two additional undescribed species have been reported from China and 
northern Laos (Assing \& Feldmann 2014; Feldmann et al. 2014). The five species currently assigned to the genus Nipponolathrobium Watanabe, 2012, all of them confined to Japan, probably belong to Macromene, too. The present study is based on Staphylinidae material collected during a field trip conducted by Michael Schülke (Berlin) and the author to eastern Yunnan, as well as on material collected by Vasily Grebennikov (Ottawa) in the Emei Shan, Sichuan. This material included numerous undescribed species, among them three of Domene.

\section{Material and methods}

The material treated in this study is deposited in the following collections:

$\begin{array}{ll}\text { CAS } & \text { Chinese Academy of Sciences, Beijing } \\ \text { cAss } & \begin{array}{l}\text { author's private collection } \\ \text { private collection Benedikt Feldmann, } \\ \text { Münster } \\ \text { private collection Guillaume de Rougemont, }\end{array} \\ \text { cRou } & \begin{array}{l}\text { Oxford } \\ \text { private collection Michael Schülke, Berlin } \\ \text { cSch }\end{array} \\ \text { cSme } & \text { private collection Aleš Smetana, Ottawa }\end{array}$

The morphological studies were conducted using a Stemi SV 11 microscope (Zeiss Germany) and a Jenalab compound microscope (Carl Zeiss Jena). The images of external characters and of the aedeagi in dry preparation were created using a photographing device constructed by Arved Lompe (Nienburg) and CombineZ software. A digital camera (Nikon Coolpix 995) was used for the remaining photographs. The map was created using MapCreator 2.0 (primap) software.

Body length was measured from the anterior margin of the mandibles (in resting position) to the abdominal apex, the length of the forebody from the anterior margin of the mandibles to the posterior margin of the elytra, head length from the anterior margin of the frons to the posterior constriction of the head, elytral length at the suture from the apex of the scutellum to the posterior margin of the elytra (at the suture), and the length of the aedeagus from the apex of the ventral process to the base of the aedeagal capsule. The "parameral" side (i.e., the side where the sperm duct enters) is referred to as the ventral, the opposite side as the dorsal aspect.

\section{Descriptions of new species}

\section{Domene (Macromene) affimbriata spec. nov. (Figs 1-12, Map 1)}

Type material: Holotype $0^{\star}$ : "CHINA [22] - Yunnan, SE Pingbian, primary forest, $22^{\circ} 54^{\prime} 31^{\prime \prime N}, 103^{\circ} 41^{\prime} 44^{\prime \prime} \mathrm{E}$, 2100 m, 27.VIII.2014, V. Assing / Holotypus ơ Domene affimbriata spec. nov., det. V. Assing 2014" (cAss).
Paratypes: 1 ㅇ: same data as holotype (cAss); $30^{\top} 0^{\star}$, 1 : : same data as holotype, but leg. M. Schülke (cSch, cAss); 1 ex. without abdomen: "CHINA [22a] - Yunnan, SE Pingbian, primary forest, $22^{\circ} 54^{\prime} 31^{\prime \prime} \mathrm{N}, 103^{\circ} 41^{\prime} 44^{\prime \prime} \mathrm{E}$, 2100 m, 28.VIII.2014, V. Assing" (cFel).

Etymology: The specific epithet (Latin, adjective: not fimbriate) alludes to the absence of a palisade fringe at the posterior margin of the male tergite VII.

Description: Body length $10.5-11.5 \mathrm{~mm}$; length of forebody $5.7-6.1 \mathrm{~mm}$. Forebody as in Fig. 1. Coloration: body black, except for the reddish posterior margins of the abdominal segments VII and VIII; legs with the femora blackish-brown (base only slightly and narrowly paler), the protibiae brown to dark-brown, the meso- and metatibiae yellowish to yellowish-brown, and the tarsi dark-yellowish; antennae dark-reddish to reddish-brown (apical half usually slightly paler than basal half) with antennomere I more or less extensively blackish.

Head (Fig. 2) approximately as broad as long or weakly transverse, widest behind eyes; punctation rather fine, distinctly umbilicate, and very dense, rendering the surface rather matt. Eyes approximately half as long as temples from posterior margin of eye to posterior constriction in dorsal view, or slightly longer. Antenna (Fig. 3) 3.7-4.2 mm long and rather slender.

Pronotum (Fig. 4) 1.15-1.22 times as long as broad and approximately 0.95 times as broad as head; median portion of lateral margins more or less subparallel in dorsal view; punctation similar to that of head, but slightly less fine; midline with interrupted narrow glossy line of variable length.

Elytra (Fig. 5) 0.75-0.80 times as long as pronotum, each elytron with three more or less distinct and more or less irregular longitudinal narrowly elevated ridges; disc more or less distinctly impressed in the middle; suture elevated; macropunctation coarse, irregular, partly confluent, and partly somewhat seriate; interstices with irregular micropunctation, otherwise not microsculptured.

Hind wings reduced. Protarsomeres I-IV rather weakly dilated in both sexes, without sexual dimorphism.

Abdomen approximately as broad as elytra; punctation extremely fine and dense on tergites III-VI, even finer, but somewhat less dense on tergites VII and VIII; anterior impressions of tergites III-VI with coarse and somewhat irregular punctation; microreticulation distinct on tergites III-VI, shallow on tergites VII-VIII; posterior margin of tergite VII usually without palisade fringe (narrow rudiments in one specimen visible); tergite VIII with convex posterior margin.

$\sigma^{*}$ : sternite VII (Fig. 6) with unmodified pubescence, posterior margin broadly and weakly concave; sternite VIII (Figs 7-8) 1.15-1.22 times as broad as long, posterior excision rather broad and shallow, on either side of this excision with a cluster of moderately modified black setae, postero-median portion without modified setae; aedeagus (Figs 9-10) approximately $1.15 \mathrm{~mm}$ long; 




1
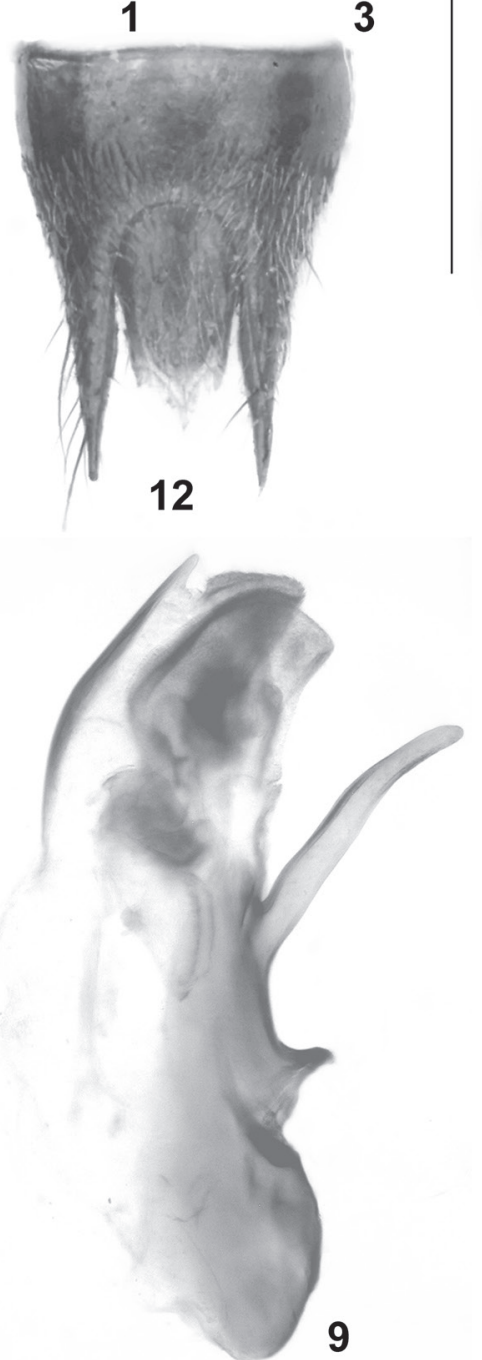

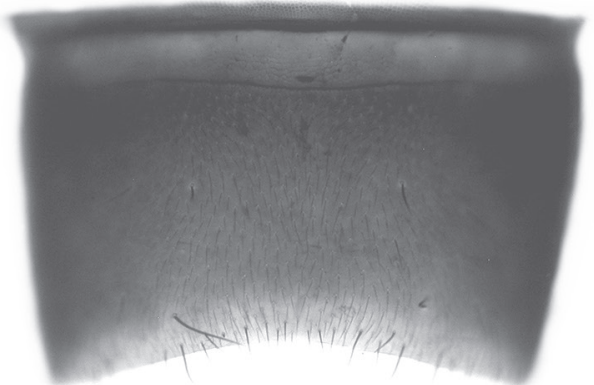

6
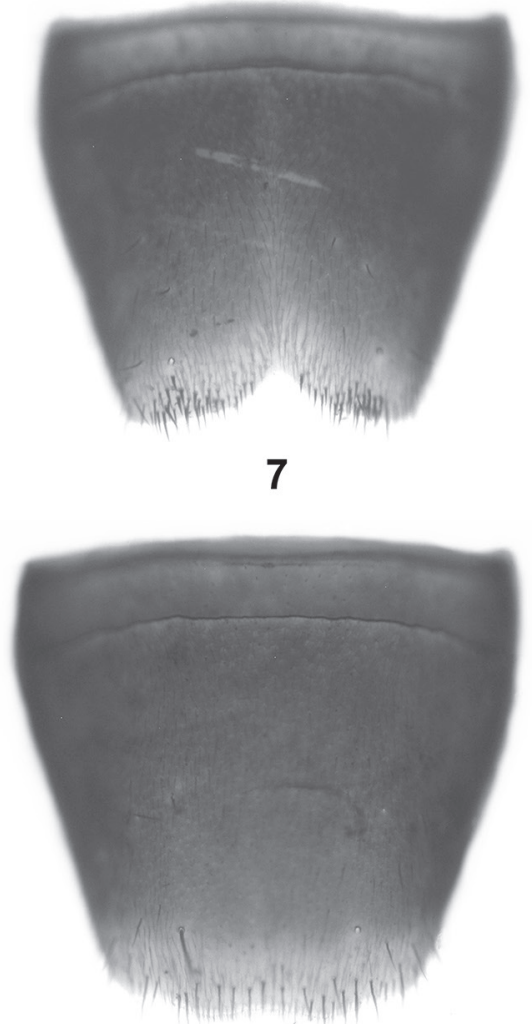

11

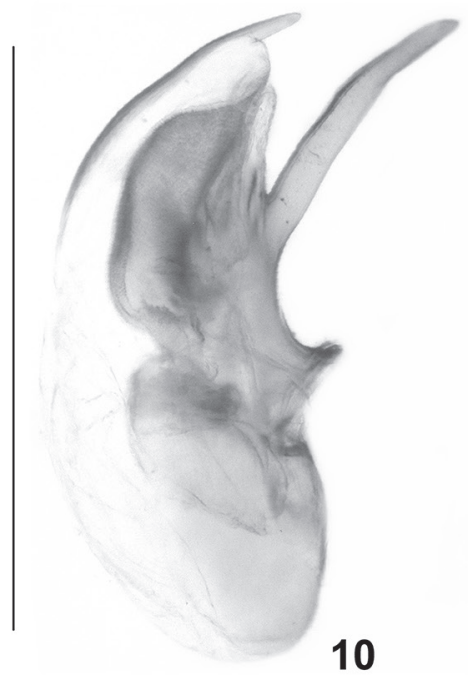



2



4

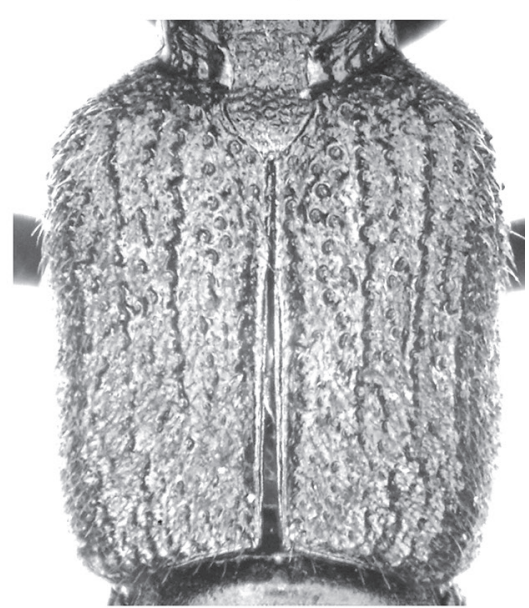

5

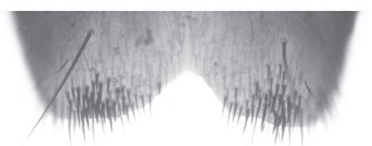

8

Figs 1-12: Domene affimbriata spec. nov.: forebody (1); head (2); antenna (3); pronotum (4); elytra (5); male sternite VII (6); male sternite VIII (7); posterior portion of male sternite VIII (8); aedeagus in lateral view (9-10); female sternite VIII (11); female tergites IX-X (12). Scale bars: $1.0 \mathrm{~mm}$. 
ventral process very slender, distinctly curved at apical third in lateral view; dorsal plate lamellate and moderately sclerotized, with long apical and very short, weakly sclerotized basal portion; internal sac with a semi-transparent apical structure and with additional membranous structures.

오 sternite VIII (Fig. 11) weakly transverse, posterior margin truncate in the middle; tergite IX (Fig. 12) with rather long and apically acute postero-lateral processes; tergite X (Fig. 12) posteriorly acute in the middle.

Comparative notes: Based on the external (surface of elytra very uneven and with irregular longitudinal ridges; hind wings and palisade fringe at the posterior margin of tergite VII reduced) and particularly on the male sexual characters (sternite VII without modified setae; sternite VIII with pair of clusters of modified setae posteriorly; aedeagus relatively small in relation to body size and with very slender ventral process), D. affimbriata is most closely allied to D. immarginata Assing \& Feldmann, 2014 from western Yunnan (Map 1), a species of the D. scabripennis group. The new species is distinguished from the similar D. immarginata by the somewhat finer punctation of the head and pronotum, the nearly completely blackish-brown femora (D. immarginata: basal half reddish to dark-reddish), the distinctly shallower and broader posterior excision of the male sternite VIII, and the differently shaped ventral process of the aedeagus (D. immarginata: ventral process curved in the middle), the shape of the posterior margin of the female sternite VIII (D. immarginata: weakly convex in the middle), and by the slightly longer and more slender postero-lateral processes of the female tergite IX. For illustrations of D. immarginata see Assing \& FeLdmann (2014).

Distribution and natural history: The type locality is situated in the Dawei Shan Virgin Forest Park near Pingbian in southeastern Yunnan (Map 1), not far from the border with Vietnam. The specimens were sifted from leaf litter in a primary subtropical broad-leaved forest at an altitude of $2100 \mathrm{~m}$.

\section{Domene (Macromene) praefigens spec. nov.} (Figs 13-24, Map 1)

Type material: Holotype $0^{\top}$ : "CHINA [9b] - Yunnan, mt. W Xundian, $2300 \mathrm{~m}$ mixed for., $25^{\circ} 34^{\prime} 58^{\prime \prime} \mathrm{N}, 103^{\circ} 08^{\prime} 42^{\prime \prime} \mathrm{E}$, sifted 16.VIII.2014, V. Assing / Holotypus o Domene praefigens spec. nov., det. V. Assing 2014" (cAss).

Paratypes: $5 \sigma^{\star} \sigma^{\star}, 8$ 우 [partly slightly teneral]: same data as holotype (cAss, Fel); $3 \sigma^{\star} \sigma^{\star}, 2$ ㅇ o : same data as holotype, but leg. M. Schülke (cSch, cFel); $10^{7}$ : "CHINA: Yunnan, mt. W Xundian, 25⒊ $34^{\prime} \mathrm{N}, 1^{\circ} 03^{\circ} 08^{\prime} 42^{\prime \prime} \mathrm{E}$, $2300 \mathrm{~m}$, mixed forest with alder, pine \& shrubs, litter, twigs, roots sifted, 15.VIII.2014, Schülke [CH1409]" (cSch); 1 우 [teneral]: "CHINA [4] - Yunnan, NE Kunming, $25^{\circ} 09^{\prime} 07^{\prime \prime N}, 102^{\circ} 53^{\prime} 46 " \mathrm{E}, 2280$ m, sec. pine for. with alder, 11.VIII.2014, V. Assing” (cAss); 1 \% : "CHINA:

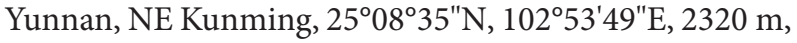
mixed forest with alder, oak, and pine, litter and mushrooms sifted, 13.VIII.2014, Schülke [CH14-06]" (cSch); $10^{\top}$ : "CHINA [12] - Yunnan, mt. WNW Wuding, mix. forest, $25^{\circ} 38^{\prime} 45^{\prime \prime} \mathrm{N}, 102^{\circ} 06^{\prime} 55^{\prime \prime} \mathrm{E}, 2390 \mathrm{~m}, 18$. VIII.2014, V. Assing" (cAss); 1 ơ: same data, but leg. Schülke (cSch); $10^{*}$ [teneral, damaged]: "China, Yunnan, Kunming, X.1986, G. de Rougemont” (cRou).

Etymology: The specific epithet is the present participle of the Latin verb praefigere (to pierce) and alludes to the acute ventral process of the aedeagus.

Description: Body length 10.0-12.0 mm; length of forebody $5.6-6.0 \mathrm{~mm}$. Forebody as in Fig. 13. Coloration: body black, except for the reddish posterior margins of the abdominal segments VII and VIII; legs with the profemora blackish, the meso- and metafemora distinctly bicoloured (basal half yellowish, apical half blackish), the protibiae reddish-brown to dark-brown, the meso- and metatibiae yellowish to yellowish-brown, the protarsi dark-brown, and the meso- and metatarsi reddish; antennae dark-brown, with the apical four antennomeres often paler brown.

Head (Fig. 14) more or less distinctly oblong, 1.061.11 times as long as broad; punctation rather fine, distinctly umbilicate, and very dense, rendering the surface rather matt. Eyes approximately half as long as temples from posterior margin of eye to posterior constriction in dorsal view, or slightly longer. Antenna (Fig. 15) 3.6-3.9 mm long and moderately slender.

Pronotum (Fig. 16) slender, 1.22-1.25 times as long as broad and approximately as broad as head, widest anteriorly and weakly tapering posteriad; punctation similar to that of head; midline with or without short and very narrow rudiment of a glossy line posteriorly.

Elytra (Fig. 17) 0.90-0.98 times as long as pronotum; disc with weakly pronounced, narrow and long lateral ridges and with rudiments of such ridges anteriorly, near scutellum with a weak elevation, without distinct impressions; suture elevated; macropunctation coarse, irregular; interstices with irregular micropunctation. Hind wings present. Protarsomeres I-IV with weakly pronounced sexual dimorphism.

Abdomen narrower than elytra; punctation extremely fine and dense; anterior impressions of tergites III-VI coarsely and somewhat rugosely sculptured; interstices with distinct microsculpture; posterior margin of tergite VII with palisade fringe; tergite VIII with posterior margin obtusely angled or convex in the middle.

$\sigma^{*}$ : protarsomeres I-IV moderately strongly dilated; sternite VII (Fig. 18) strongly tranverse, approximately twice as broad as long (length measured along the middle), with pronounced and extensive median impression, this impression with numerous strongly modified, short and stout black setae posteriorly, posterior margin broadly and deeply concave; sternite VIII (Fig. 19) distinctly 


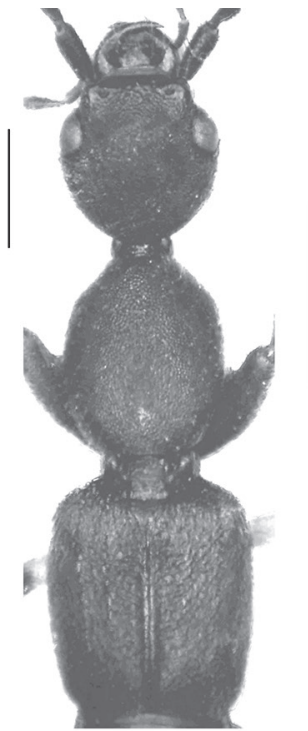

13

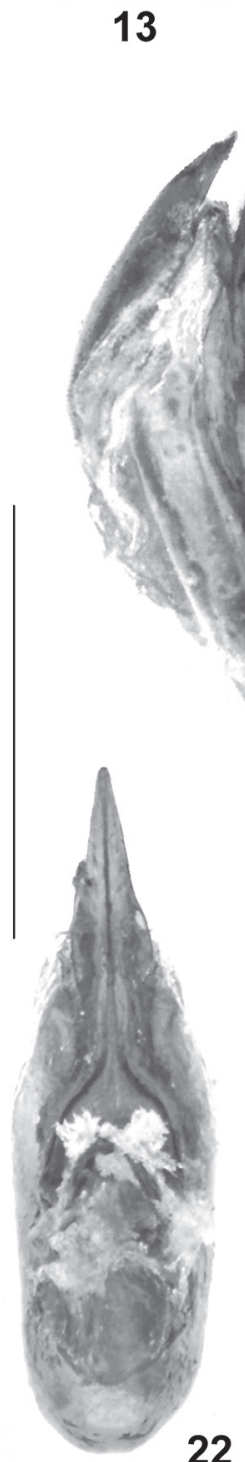

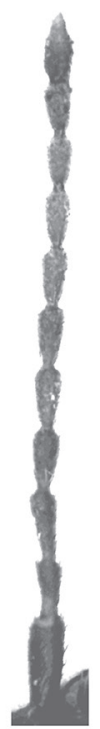

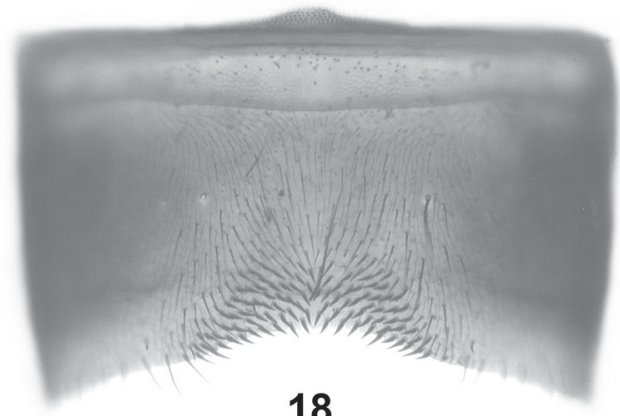

18
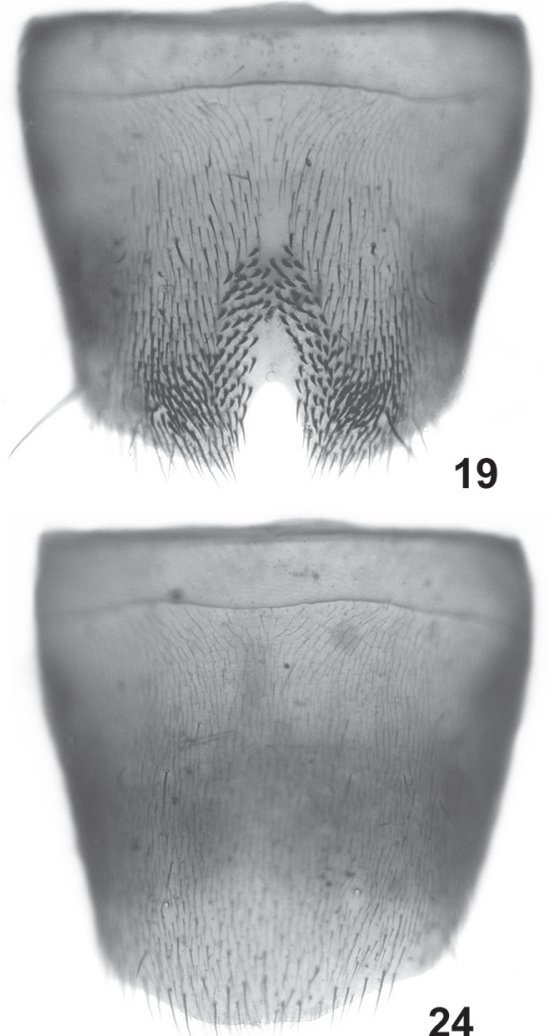

21

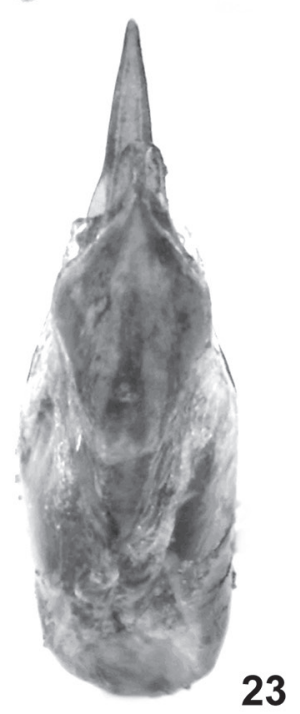



14

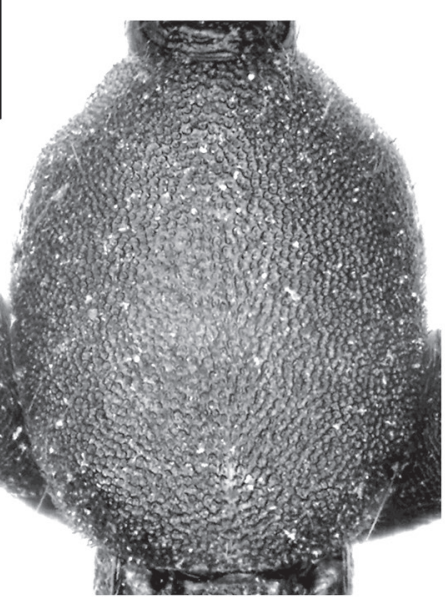

16

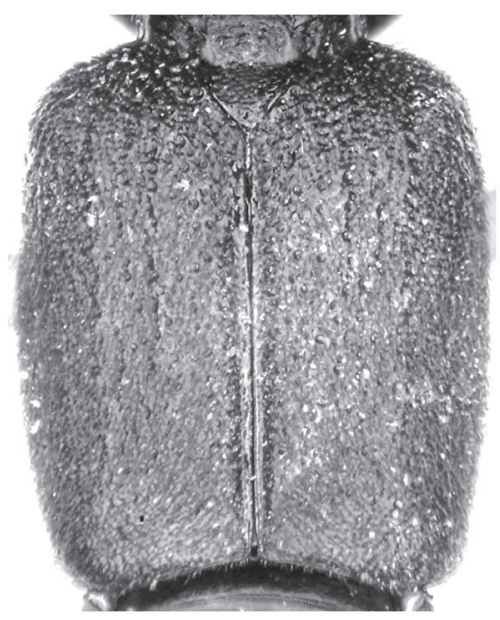

17

Figs 13-24: Domene praefigens spec. nov.: forebody (13); head (14); antenna (15); pronotum (16); elytra (17); male sternite VII (18); male sternite VIII (19); aedeagus in lateral view (20); aedeagus in dry preparation in lateral, in ventral, and in dorsal view (21-23); female sternite VIII (24). Scale bars: $1.0 \mathrm{~mm}$. 
transverse and with pronounced oblong postero-median impression, in lateral and anterior portions of this impression and on either side of the posterior excision with numerous strongly modified, short and stout black setae; posterior excision somewhat U-shaped, approximately 0.2 times as deep as length of sternite; aedeagus (Figs 20-23) approximately $1.6 \mathrm{~mm}$ long; ventral process ventrally sharply keeled and apically acute; dorsal plate with apical portion distinctly sclerotized, basally broad and apically narrowly convex, and with basal portion weakly sclerotized and short; internal sac with dark membranous apical structures and with a large dark broadly U-shaped basal sclerite.

P: protarsomeres I-IV distinctly dilated, but slightly less so than in male; sternite VIII (Fig. 24) approximately as long as broad and with broadly convex posterior margin; tergite IX with moderately long and apically acute postero-lateral processes; tergite X flat and slightly longer than antero-median portion of tergite IX.

Comparative notes: In external and sexual characters, D. praefigens is most similar to D. cuspidata Feldmann \& Peng, 2014, a species recorded from Shaanxi, Gansu, and Sichuan (Map 1), from which it differs by the coloration (D. cuspidata: humeral angles of the elytra with a reddish spot; legs uniformly yellowish to reddish), by the more deeply and broadly concave posterior margin of the male sternite VII, by the shape and chaetotaxy of the male sternite VII (D. cuspidata: posterior excision distinctly less deep and broadly $\mathrm{V}$-shaped; median portion of posteromedian impression more narrowly without setae), by the larger aedeagus with a more slender ventral process (D. cuspidata: aedeagus approximately $1.4 \mathrm{~mm}$ long), by the shape of the dorsal plate in lateral view, and by the less strongly convex posterior margin of the female sternite VIII. For illustrations of D. cuspidata see FELDMANN et al. (2014).

Distribution and natural history: The species was collected in several localities in the region to the north, northeast, and northwest of Kunming, eastern Yunnan (Map 1). The specimens were sifted from litter, particularly from deep litter layers partly under heaps of dead branches, in mixed forests and in a secondary pine forest with scattered alder at altitudes of 2280-2390 m. Some of the paratypes are slightly to distinctly teneral.

\section{Domene (Macromene) emeiana spec. nov.}

(Figs 25-39, Map 1)

Type material: Holotype $\sigma^{*}$ : "P. R. CHINA, Sichuan, Emei Shan, N2933'51", E103²0'47", 23.v.2011, 1779 m, sift03, V. Grebennikov / Holotypus ${ }^{\star}$ Domene emeiana spec. nov., det. V. Assing 2014" (CAS).

Paratypes: 1 \%: same data as holotype (cSme); $10^{*}$ : "P. R. CHINA, Sichuan, Emei Shan, N2933'00", E10321'38", 28.v.2011, 1639 m, sift08, V. Grebennikov"
(cAss); 5 우 [listed as Domene sp. in Feldmann et al. (2014)]: 'P. R. CHINA, Sichuan, Emei Shan, N29³3.6', E103²0.6', 27.iv.-5.vii.2009, 1800-2400 m, sifting 11-17, V. Grebennikov" (CAS, cSme, cAss, cFel); 1 ㅇ [identification based on a photo sent by B. Feldmann; label in Chinese, translated by Zhong Peng]: "Sichuan, Emei Shan, Jiulaodong [ca. $29^{\circ} 33^{\prime} \mathrm{N}, 103^{\circ} 21^{\prime} \mathrm{E}, 1850 \mathrm{~m}$ ], Nanchong normal college / 25-VII-1983, collector: I-116" (cRou).

Etymology: The specific epithet (adjective) is derived from the name of the mountain, where the species was discovered.

Description: Body length $8.0-9.50 \mathrm{~mm}$; length of forebody $4.4-4.7 \mathrm{~mm}$. Forebody as in Fig. 25. Coloration: forebody brown, with the humeral angles of the elytra mostly slightly and indistinctly paler; abdomen bicoloured, with segments III-VI dark-yellowish to reddish, segment VII infuscate with the anterior portion broadly, and the posterior margin narrowly yellowish to reddish, segment VIII with the anterior half and the posterior margin yellowish and with a broad transverse brown band in posterior half, segments IX-X darkyellowish to pale-reddish; legs dark-yellowish; antennae dark-reddish, with antennomere XI apically paler.

Head (Fig. 26) of conspicuously subcircular to oval shape, 1.05-1.10 times as long as broad; punctation rather fine, distinctly umbilicate, and very dense, rendering the surface rather matt. Eyes relatively small, $0.3-0.4$ times as long as temples from posterior margin of eye to posterior constriction in dorsal view. Antenna (Fig. 27) 3.0-3.3 mm long and moderately slender.

Pronotum (Fig. 28) slender, approximately 1.25 times as long as broad and 0.95-1.00 times as broad as head, lateral margins subparallel in the middle; punctation similar to that of head; midline with very short and narrow rudiment of a glossy line posteriorly, this glossy line with a fine median furrow.

Elytra (Fig. 29) short and slender, only approximately 0.6 times as long and 0.95 times as broad as pronotum; disc distinctly and extensively impressed anteriorly, without longitudinal ridges; punctation irregular and dense, very coarse in anterior half and less coarse posteriorly, partly rugose; suture elevated; Hind wings completely reduced. Protarsomeres I-IV with distinct sexual dimorphism.

Abdomen 1.2 times as broad as elytra; punctation extremely fine and dense; anterior impressions of tergites III-VI coarsely and somewhat rugosely sculptured; interstices with shallow microsculpture; posterior margin of tergite VII without palisade fringe; tergite VIII with posterior margin obtusely angled or convex in the middle (Fig. 37).

$\sigma^{*}$ : protarsomeres I-IV strongly dilated; sternites $\mathrm{V}$ and VI with shallow and rather small postero-median impression (Fig. 30); sternite VII (Figs 30-31) conspicuously tranverse, more than twice as broad as long (length measured along the middle), with pronounced and extensive 


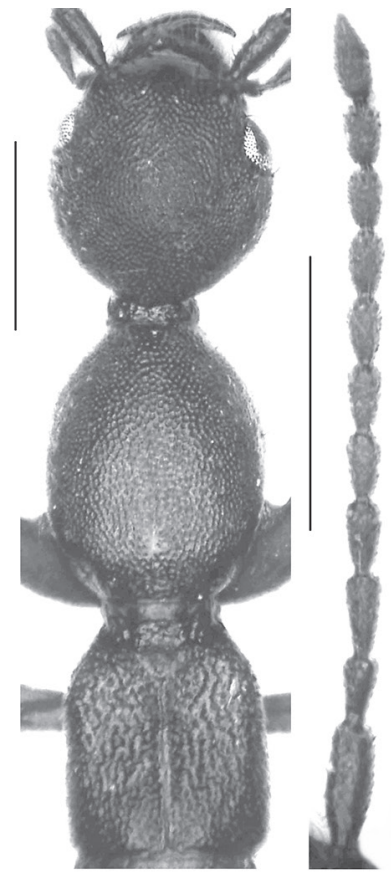

25

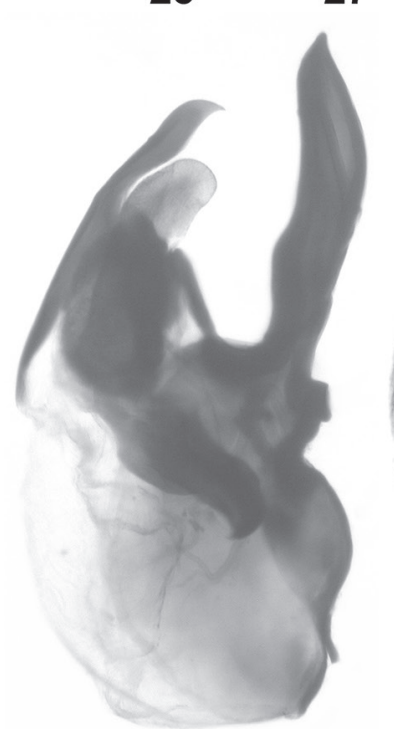

33

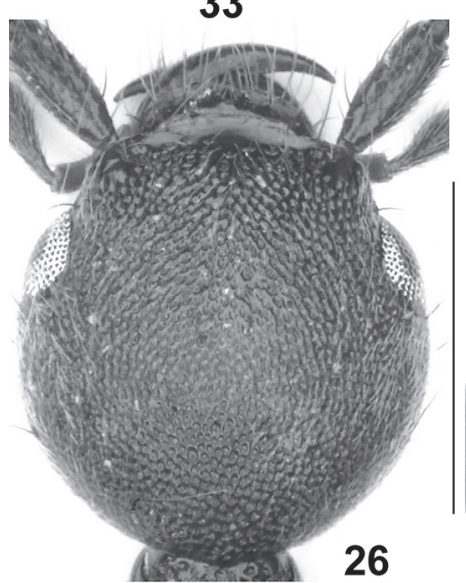

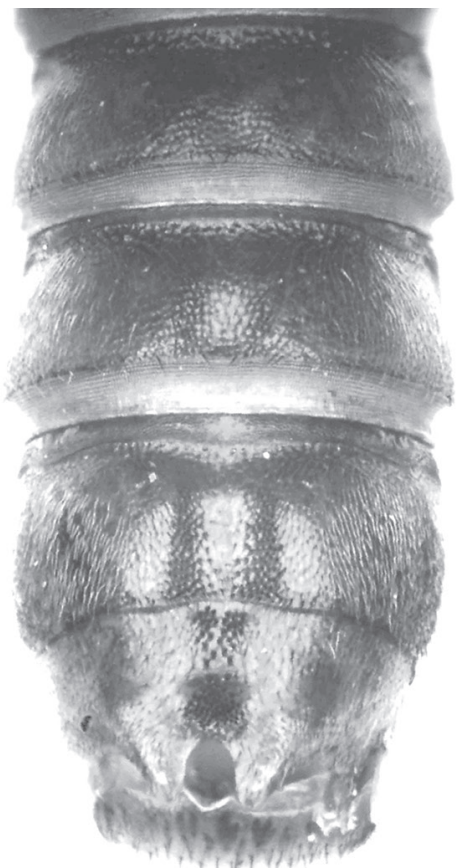

30

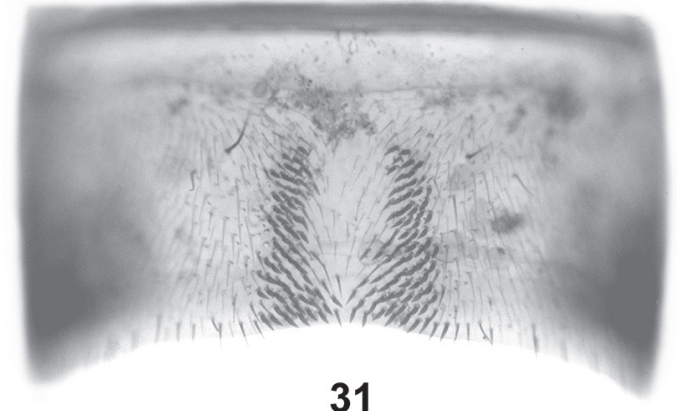

31

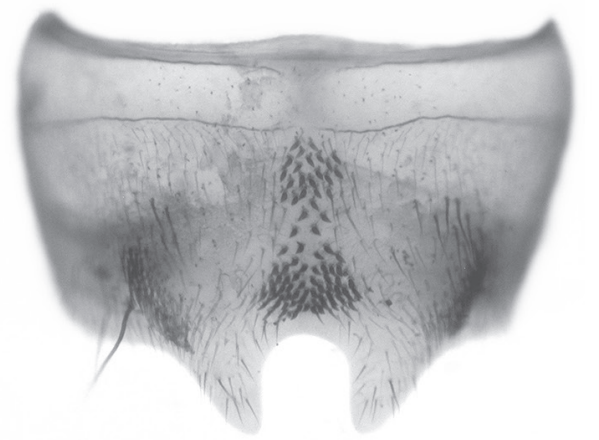

32



34

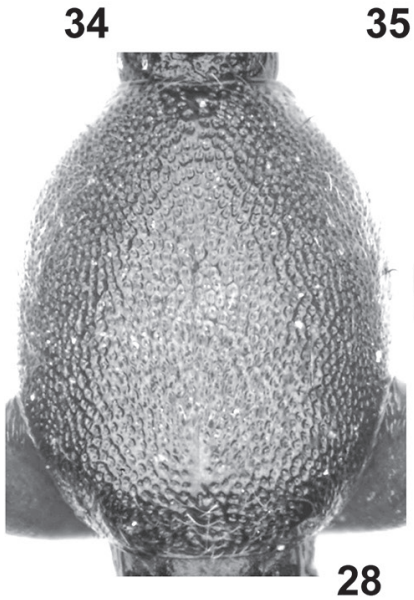

35

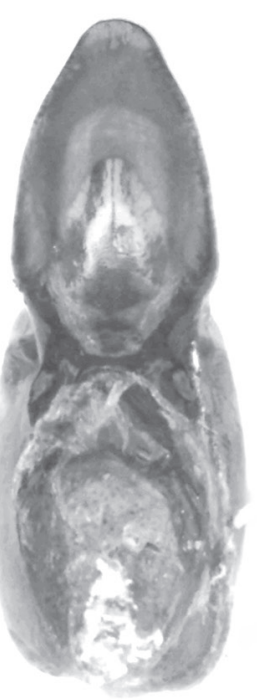

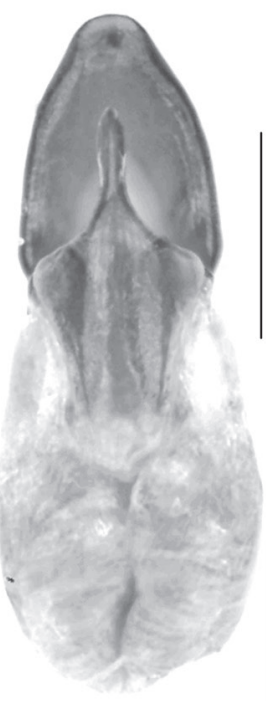

36



39
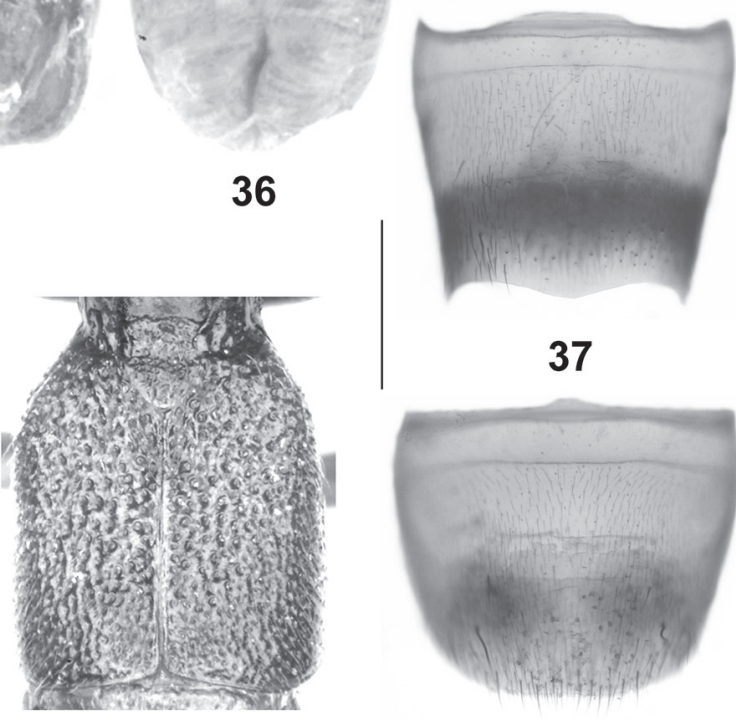

29
37

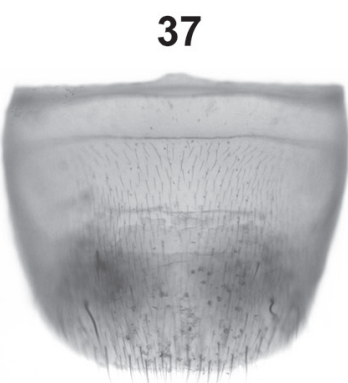

38

Figs 25-39: Domene emeiana spec. nov.: forebody (25); head (26); antenna (27); pronotum (28); elytra (29); male sternites V-VIII (30); male sternite VII (31); male sternite VIII (32); aedeagus in lateral view (33); aedeagus in dry preparation in lateral, in ventral, and in dorsal view (34-36); female tergite VIII (37); female sternite VIII (38); female tergites IX-X (39). Scale bars: 25-32: 1.0 mm; 33-39: $0.5 \mathrm{~mm}$. 
median impression, this impression with numerous strongly modified, short and stout black setae in characteristic arrangement, posterior margin broadly concave; sternite VIII (Figs 30, 32) strongly transverse, nearly 1.5 times as broad as long, with a rather pronounced oblong postero-median impression with a (posteriorly denser) cluster of numerous strongly modified, short and stout black setae, posterior margin with a long and nearly acute process on either side of the U-shaped posterior excision; aedeagus (Figs 33-36) approximately $1.5 \mathrm{~mm}$ long and of very distinctive morphology; ventral process massive, blade-shaped, and strongly sclerotized; dorsal plate distinctly sclerotized, basally lamellate and apically extending into a narrow and acute process; internal sac with dark sclerites and with apical structure of distinctive shape. i : protarsomeres I-IV distinctly dilated, but somewhat less so than in male; sternite VIII (Fig. 38) distinctly transverse, approximately 1.35 times as broad as long, and with broadly convex posterior margin; tergite IX (Fig. 39) with very short antero-median portion and with relatively short and apically acute postero-lateral processes; tergite $\mathrm{X}$ flat and approximately 3.5 times as long as antero-median portion of tergite IX (Fig. 39).

Comparative notes: This highly distinctive species is separated from all other Domene species recorded from China by numerous external and sexual characters, i.e., the coloration of the abdomen, the nearly circular head, the smaller eyes, distinctly shorter and more slender elytra, the conspicuous shapes and chaetotaxy of the male sternites VII and VIII, the completely different



Map 1: Distributions of the named Domene species in China and Taiwan (new species: black symbols), based on literature (FELDMANN et al. 2014) and examined records: D. cuspidata (white circles); D. immarginata (white squares); D. praefigens (black circles); D. affimbriata (black square); D. emeiana (black star); other species pooled (white diamonds). For the individual distributions of the pooled species see Assing \& Feldmann (2014) and Feldmann et al. (2014). 
morphology of the aedeagus (shapes of ventral process, of dorsal plate, and of internal structures), the strongly transverse female sternite VIII, and the remarkably short antero-median portion of the female tergite IX. Except for D. immarginata and D. affimbriata, it is additionally distinguished from all other Chinese representatives of the genus by the reduced wings and the absence of a palisade fringe at the posterior margin of tergite VII. In fact, D. emeiana is so derived in so many respects that closer affiliations with any other Domene species known from China are not evident.

Distribution and natural history: The adaptive reductions of the eyes, the wings and the palisade fringe at the posterior margin of tergite VII, as well as the absence of records from other regions suggest that D. emeiana is endemic to the Emei Shan in Sichuan (Map 1). The specimens were sifted at altitudes between 1640 and $2400 \mathrm{~m}$.

\section{Acknowledgements}

I am indebted to Michael Schülke (Berlin) and Aleš Smetana (Ottawa) for making their material available for this study. Benedikt Feldmann (Münster) proof-read the manuscript. Zhong Peng (Shanghai) translated the Chinese labels of a paratype of D. emeiana.

\section{References}

Assing, V. \& Feldmann, B. 2014: On Domene scabripennis Rougemont and its close relatives (Coleoptera: Staphylinidae: Paederinae). - Linzer Biologische Beiträge 45 (2): 499-514.

Feldmann, B.; Peng, Z. \& Li, L.-Z. 2014: On the Domene species of China, with descriptions of four new species (Coleoptera, Staphylinidae). - ZooKeys 456: 109-138. 